\title{
Discursos midiáticos sobre questões ambientais: um estudo na perspectiva das representações sociais
}

Este artigo parte do pressuposto de que enunciados só adquirem sentido nos contextos em que são produzidos, apresentando significações diferenciadas, a partir de quem, como e para quem são pronunciados, e em que suportes são veiculados. Considera-se, então, que as mídias podem contribuir significativamente para a aquisição de hábitos e costumes de leitores, além de apresentarem uma perspectiva ideológica de quem produz, com possíveis contrapontos às ideologias de quem os recebe. Nesse contexto, faz-se necessário destacar a importância do gênero textual propaganda que, ao divulgar um produto, veicula uma representação do produtor, e busca alcançar a adesão não apenas de consumidores diretos, mas também de parcelas da população. Posto isto, o presente trabalho tem como objeto de discussão propagandas da empresa Monsanto - empresa de produção agricola em escala mundial, bem como propagandas da população. Posto isto, o presente trabalho tem como objeto de discussão propagandas da empresa Monsanto - empresa de produção agrícola em escala mundial, bem como propagandas ambiental, soberania alimentar, agroecologia e representações sociais, buscando identificar, nos textos escolhidos, as concep̧̧̃̃es que os permeiam, bem como os 'lugares' sociais que buscam ocupar aqueles que os produzem. As discussões valem-se de subsídios explicitados pela Teoria das Representações Sociais, pela Análise do Discurso e pela Teoria Sociointeracionista da linguagem. Dessa maneira, foram analisados um total de quatro textos, sendo dois da Monsanto e dois de ONGs de diferentes países. O objetivo é apresentar contrapontos e relaçõe entre os discursos, observando como esses podem se constituir ou se valer de representaç̧ões sociais já constituídas para alcançar a aderência do consumidor. Contextualizam-se as mídias a partir de suas condições de producão, determinando o público-alvo de seus discursos e ações, retratadas nas propagandas. A perspectiva teórica e metodológica considera, além das teorias mencionadas, a Teoria do Agendamento. As conclusões iniciais que se podem inferir relacionam-se à percepção da mídia como produtora de um tratamento da informação refratando informaç̃̃es que podem contribuir para a construção/consolidação de representaç̃̃es sociais e a existência de uma dicotomia, propagada pela mídia.

Palavras-chave: Mídia; Agroecologia; Soberania alimentar; Educação ambiental; Representações sociais.

\section{Media discourses on environmental issues: a study from the perspective of social representations}

This article assumes that utterances only make sense in the contexts in which they are produced, presenting different meanings, from whom, how and to whom they are pronounced, and in which medis of those who produce, with possible counterpoints to the ideologies of those who receive them. In this context, it is necessary to highlight the importance of the textual advertising genre, of those who produce, with possible counterpoints to the ideologies of those who receive them. In this context, it is necessary to highlight the importance of the textual advertising genre,
which, when promoting a product, conveys a representation of the producer, and seeks to achieve the adhesion not only of direct consumers, but also of portions of the population. That which, when promoting a product, conveys a representation of the producer, and seeks to achieve the adhesion not only of direct consumers, but also of portions of the population. That
said, the present work has as its object of discussion advertisements from Monsanto - a worldwide agricultural production company, as well as advertisements from NGOs, whose purpose is said, the present work has as its object of discussion advertisements from Monsanto - a worldwide agricultural production company, as well as advertisements from NGOS, whose purpose is
to clarify the population on the issue of food sovereignty. The structure of the article is based on an initial discussion about conceptions of environmental education, food sovereignty, agroecology and social representations, seeking to identify, in the chosen texts, the concepts that permeate them, as well as the social 'places' that seek to occupy those. that produce them. The discussions use subsidies made explicit by the Theory of Social Representations, Discourse Analysis and the Sociointeractionist Theory of Language. Thus, a total of four texts were analyzed, two from Monsanto and two from NGOs from different countries. The objective is to present counterpoints and relations between the discourses, observing how these can be constituted or use ocial restion the

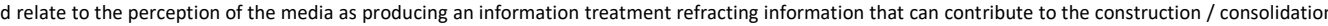
of social representations and the existence of a dichotomy, propagated by the media.

Keywords: Media; Agroecology; Food sovereignty; Environmental education; Social representations.

Topic: Agroecologia

Reviewed anonymously in the process of blind peer.

Leonardo de Miranda Siqueira (iD)

Instituto Federal do Espírito Santo, Brasil

Lattes: http://lattes.cnpq.br/1796320260592037

http://orcid.org/0000-0001-9632-1463

leobs06@hotmail.com

Elizabeth Moreira Gomes (id

Instituto Federal do Norte de Minas Gerais, Brasil

http://lattes.cnpq.br/2300460725207329

http://orcid.org/0000-0003-3711-1663

elizabeth.gomes@ifnmg.edu.br

Carlos Augusto Pereira da Silva (it

Instituto Federal do Norte de Minas Gerais, Brasil

http://lattes.cnpq.br/2843639478540582

http://orcid.org/0000-0001-8949-3152

capsambiental@gmail.com

dis

DOI: 10.6008/CBPC2674-645X.2019.002.0001
Received: 02/07/2019

Approved: 05/09/2019

Maria Isabel Antunes Rocha (iD

Universidade Federal de Minas Gerais, Brasi

http://lattes.cnpq.br/2300460725207329

http://orcid.org/0000-0002-4044-6723

isabelantunes@fae.ufmg.br
Referencing this:

SIQUEIRA, L. M.; GOMES, E. M.; SILVA, C. A. P.; ROCHA, M. I. A. Discursos midiáticos sobre questões ambientais: um estudo na perspectiva das representações sociais. Agriculturae, v.1, n.2, p.1-17, 2019. DOI: http://doi.org/10.6008/CBPC2674-645X.2019.001.0001 


\section{INTRODUÇÃO}

Contextualizaremos, neste trabalho, as concepções de agroecologia, soberania alimentar, educação ambiental e representações sociais (RS) na perspectiva midiática. A educação ambiental (EA) é concebida neste trabalho como ferramentas utilizadas para tratar de temas ambientais, disseminados, principalmente, pelos meios de comunicação. A soberania alimentar trata dos problemas relacionados à situação alimentar da humanidade. Essa terminologia surge no contexto dos movimentos sociais, em contraposição ao termo midiático segurança alimentar e se relaciona não apenas à quantidade de alimentos para suprir necessidades da humanidade, como é o caso da segurança alimentar, mas também com a qualidade destes com vistas à garantia de saúde e vida das pessoas.

A agroecologia é um movimento social militante da produção sustentável de alimentos pelos agricultores familiares baseado em técnicas agronômicas alternativas sem uso de agrotóxico. Na última década, a agroecologia ligada a movimentos sociais, expande sua pauta, incorporando questões políticosociais, tais como: democracia, feminismo, racismo, patriarcado, entre outras bandeiras. Nessa perspectiva, a agroecologia propõe formas de trabalho e de produção ligadas à terra, que se opõem às formas de produção do agronegócio.

Ambas, agricultura familiar e agronegócio, por apresentarem perspectivas diferentes entre si, buscam construir/divulgar para a sociedade de modo geral, representações de formas de trabalho ligadas à produção de alimentos, que buscam alcançar a adesão não apenas de consumidores potenciais, mas, sobretudo, buscam alcançar a adesão da sociedade em relação a um modo de vida, que coaduna com uma visão sobre o 'uso' e função da terra na/para a produção de alimentos. Nesse sentido, cada uma dessas perspectivas apresenta um conjunto de textos midiáticos com vistas ao alcance de divulgação de seu trabalho de modo a garantir a adesão do maior número de diversos grupos populacionais, possíveis consumidores.

Este trabalho propõe analisar as produções midiáticas desses dois grupos: o primeiro, representado por Organizações Não Governamentais - ONGs, que adotam a perspectiva da agricultura familiar, com uma produção mais sustentável e mais 'natural'; o segundo, as produções midiáticas de uma empresa - Monsanto, cuja produção se relaciona ao agronegócio. Busca-se, dessa forma, evidenciar as estratégias discursivas dessas duas vertentes, com vistas ao alcance da adesão de diferentes grupos sociais, de modo a ampliar o consumo de alimentos produzidos a partir de técnicas e formas de produção antagônicas, implicando um modo de vida profundamente diferente entre tais proposições.

Para analisar a questão proposta, considerou-se pertinente trabalhar com as representações sociais (MOSCOVICl, 2012) como referência teórica, visto que o interesse é compreender as formas de pensar, sentir e agir das pessoas sobre propagandas com a temática ambiental, orientada pela perspectiva moscoviciana. Para Jodelet (2001), a representação social é uma forma de conhecimento, socialmente elaborada e compartilhada, ela permite a compreensão do processo representativo de um sujeito sobre algum objeto.

Guimelli et al. (2015) afirma que Moscovici considerara que as representações não são produtos de uma sociedade como um todo, mas sim, dos grupos sociais que compõem essa sociedade. Por outro lado, 
ainda segundo Guimelli et al. (2015), Moscovici enfocará processos de comunicação, considerados como explicativos do surgimento, construção, reconstrução, propagação de RS. O primeiro ponto permite conceber um pensamento social que permanece sobre determinado pelas estruturas da sociedade, mas também pressupõe uma intensa atividade de sujeitos inseridos nessas estruturas, de modo a modificá-las e agir sobre elas. Assim, diferentes grupos sociais apresentam diversas RS de um 'mesmo' objeto em determinada sociedade/grupo.

\section{METODOLOGIA}

Realce-se que o presente artigo tem como objeto a divulgação midiática de duas perspectivas (econômicas, políticas, científicas e sociais) de, pelo menos, duas posições em relação a formas de produção de alimentos, que se ligam evidentemente a formas de vida de pessoas comuns no interior de uma dada sociedade. De um lado, toma-se a construção da imagem pública de uma grande empresa produtora de alimentos a Monsanto e, de outro, consideram-se os posicionamentos de ONGs, em relação a essa produção, consideradas as atitudes (públicas e publicizadas) dessas duas vertentes em relação ao ambiente, à produção e ao consumo de alimentos.

Foram selecionados 04 (quatro) textos predominantemente imagéticos, construídos com a finalidade de facilitar a divulgação/absorção de metáforas pelo grande público. São encontradas em Marková (2017) reflexões acerca da construção metafórica a partir do uso de imagens. Esta se constitui, pois, a perspectiva de análise que se pretende abordar no presente artigo. Quais as metáforas construídas em relação à divulgação do trabalho humano no ambiente e na produção de alimentos? Que RS as propagandas/textos selecionadas para este trabalho evocam e de que estratégias discursivas/imagéticas elas se valem? Até que ponto tais imagens/metáforas se valem de pensamentos 'míticos' e/ou de pensamentos científicos para divulgarem suas perspectivas e alcançarem a adesão da sociedade? São essas questões que norteiam as análises apresentadas no presente artigo.

\section{DISCUSSÃO TEÓRICA}

\section{Agroecologia}

Desde a década de 1920, diferentes correntes de agricultura alternativa, que já estavam sendo desenvolvidas, necessitavam de uma fundamentação teórica, que resultou no surgimento da agroecologia, a partir da década de 1970. Seu surgimento está relacionado a ideia de uma nova agricultura integrada ao meio ambiente, em resposta aos críticos destes movimentos que consideravam um retrocesso no passado da agricultura (ASSIS et al., 2002).

A agroecologia ganha importância a partir de meados do século XX, quando vários países latinoamericanos aderiram à intitulada Revolução Verde, cuja meta era o aumento da produção a partir do uso abusivo de insumos químicos, variedades geneticamente modificadas e uma extensão rural voltada para esse modelo agrícola. A agroecologia se insere, a partir de então, num debate da sustentabilidade do 
desenvolvimento, adotando um padrão tecnológico produtivo que não use de forma predatória os "recursos naturais" e muito menos modifique agressivamente a natureza (ALTIERI, 2004).

As primeiras discussões sobre Agroecologia (AYUKAWA, 2005), no Brasil, têm início na década de 1980, resultado de um movimento contrário ou alternativo às consequências da modernização agrícola no país, contrapondo uma política agrária excludente, baseado no crescimento econômico. Desde então, diversas concepções de agroecologia surgiram, entre elas a que ganhou força e que assumiu um aspecto mais pedagógico foi o estudo da agricultura, consideradas as questões sociais, culturais, ambientais e econômicas de maneira interrelacionada.

O processo de "modernização da agricultura" potencializado pelo estado e por grandes empresas de capital nacional e internacional (HESPANHOL, 2008) provocou uma debandada de trabalhadores assalariados, temporários e migratórios, porque se explora a terra por um determinado tempo de modo a 'sugar' sua fertilidade, e posteriormente, muda-se para exploração em outros locais.

Além do mais, este período é marcado pela forte migração de agricultores para o meio urbano, isto porque com uma forte contribuição da mídia, o campo passou a ser visto como lugar de grandes produções, que dispensava a presença constante do homem; divulga-se a ideia que quem ali morava estava condenado a viver no atraso. Parte de agricultores resistentes começa a se organizar em movimentos sociais, contrapondo este forte aparato de exploração dos trabalhadores e contrapondo também o avanço dos pacotes tecnológicos vendidos para agricultura produtivista.

Para Leão et al. (2015) o conceito de campo vem se afirmando na prática social e científica como possibilidade de superação dos limites historicamente construídos em torno do termo rural para designar o território, as pessoas e suas práticas relativas a atividades desenvolvidas em sua relação com a terra. Assim, o termo passa a designar o lugar, os sujeitos e suas práticas acrescentando a intencionalidade de resistência e luta por melhores condições de vida dos povos camponeses. Recorremos a Fernandes (2006) para a compreensão das dimensões territoriais, que entre elas estão: educação, cultura, produção, trabalho, infraestrutura, organização política, mercado, dentre outras. Tais relações se constituem como relações sociais, sendo interativas, complexas e, por isso mesmo, impossível pensá-las em separado.

O avanço das tecnologias agrícolas propagadas pelo agronegócio e a necessidade de políticas públicas e práticas que olhassem para o meio ambiente como indispensável para sobrevivência humana contribuiu para o fortalecimento da agroecologia a partir dos anos de 1980. Para Caporal (2015), a agroecologia pode ser definida a partir de um enfoque científico que propicia ferramentas para transição do atual modelo agrícola para um modelo sustentável, buscando em um horizonte temporal, a construção de novos saberes socioambientais que alimentem um processo de transição agroecológica.

Importante destacar que a agroecologia tem como sujeitos os agricultores familiares, em pequenas faixas de terras, a mão de obra vem da família ou da comunidade; estando organizados em associações de pequenos agricultores que buscam acesso a políticas públicas para garantia de sua subsistência na propriedade, sua produção é comercializada na região, o que gera renda para mesma. 
Diferentemente, o agronegócio tem como seus sujeitos as grandes empresas e grandes proprietários concentrados em enormes latifúndios e num modelo excludente, concentrador de renda, sendo que a sua base de sua produção são as commodities ${ }^{1}$ agrícolas, estas em razão de seu peso nas exportações têm forte incentivo governamental nas políticas de crédito e um grande aparato midiático.

Para Guterres (2006), alguns problemas em relação aos alimentos transgênicos ${ }^{2}$ e à saúde das pessoas, mesmo que não haja consenso na comunidade científica, são notórios, entre eles estão: mortes, alergias, resistência antibiótica, retardo no crescimento, intoxicação, além de outros casos como queda de prenhez de suínos alimentados com milho transgênico. Alinhado em Guterres (2006), o agronegócio brasileiro mistura a modernidade técnica com atraso nas relações sociais, gera pouco emprego e causa um êxodo rural que os centros urbanos não são capazes de absorver com dignidade.

Ao contrário do agronegócio, a agricultura camponesa, protagonizada pela agroecologia, busca romper com esta lógica capitalista de produção, cuja matriz de produção agroecológica vem sendo proposta e defendida pelos movimentos sociais como uma alternativa de enfrentamento ao modelo de modernização agrícola anunciado pelos meios de comunicação desde os anos 1970 (início da Revolução Verde no Brasil).

\section{Soberania alimentar}

Para entender e conceituar a soberania alimentar, é preciso viajar nos anos de 1930, quando os especialistas em nutrição alertavam para falta de alimentos para gerações futuras, ao passo que, simultaneamente, os economistas recomendavam reduzir a produção de alimentos para resolver o problema dos excedentes. A partir deste dualismo, percebeu-se que a fome existe para numerosas populações e que há excedentes agrícolas impossíveis de serem postas no mercado.

Até o início dos anos de 1980, considerava-se que os grandes déficits alimentares eram influenciados por razões climáticas e por conflitos políticos. Em meados dos anos de 1980 quando a disponibilidade alimentar aumentou consideravelmente, outro debate ganhou fôlego. Tal debate dizia respeito às condições ecológicas do meio ambiente. Este debate acontece em meio ao aparecimento de ameaças globais resultantes do reaquecimento do planeta e do alerta sobre o desflorestamento dos bosques tropicais até o debate sobre a biodiversidade (CHONCHOL, 2005). Para Bernstein (2015), soberania alimentar tem seu marco teórico, definido por

[...] noções do capitalismo como "sistema mundial" que abrange uma gama de apelos, desde os panfletários (agit-prop) aos mais analíticos. O "capitalismo" - ou sua atual fase de globalização - é apontado como a fonte da agricultura empresarial industrializada, com distintas ênfases em vários aspectos ou momentos das narrativas do capitalismo, como recém ilustrado. Às vezes, "capitalismo" torna-se simplesmente um sinônimo para agricultura industrializada, ou é intercambiável com ideologias da "modernidade" (e projetos modernizantes) - com base em certas concepções de racionalidade, eficiência e conquista da natureza - utilizado para constituir a ordem alimentar mundial (tese) contra a qual a soberania alimentar define a si própria (antítese).

\footnotetext{
${ }^{1}$ Commodities são mercadorias, principalmente minérios e produtos agrícolas, que são produzidas em larga escala e comercializadas em nível mundial, negociados em bolsa de valores.

${ }^{2}$ Transgênicos são organismos vivos (plantas e animais) geneticamente modificados para alta produção e resistência a pragas e doenças. Estes são patenteados pelo agronegócio.
} 
A soberania alimentar surge numa mistura de agricultura capitalista com ideologias capitaneadas por entidades ambientais, até porque a termologia originária e apropriada por correntes teóricas era a de 'segurança alimentar'; conceitualmente, essa tem a preocupação com a quantidade de alimentos para humanidade, já a soberania alimentar leva em consideração a qualidade e as formas como estes alimentos são produzidos.

Rosset (2003) aponta que segurança alimentar é quando as pessoas estão certas que terão seus alimentos todos os dias. Porém, fica obscuro de onde vem esse alimento e como ele é produzido. Ainda de acordo com Rosset (2003), o conceito de soberania alimentar vai além do conceito de segurança alimentar, que foi destituído do significado real, ele é uma questão de soberania nacional de independência dos caprichos da economia global e dos grandes países produtores de commodities.

Conforme já percebido por Souza (2009), existe uma disputa por conceitos, o que causa certa confusão teórica, de certo modo compreensível, já que eles vêm sendo trabalhos desde os anos 1990 e que ao longo deste tempo muitos esforços foram feitos no sentido de defini-los e conceituá-los. Ainda de acordo com Souza (2009) a soberania alimentar deve ser discutida, considerando:

\begin{abstract}
Este debate político-ideológico sobre a segurança e a soberania alimentar, permeia então questões como a produção de alimentos, a matriz energética e com ela a monocultura, os movimentos sociais e o agronegócio, a significativa demanda por alimentos e com ela a especulação através dos mercados de commodities, etc., que nos remete a uma crise na produção agrícola não pela ausência de produtos, mas pela destinação que se tem dado a eles, e ainda ao não-debate amplo e público sobre a segurança e soberania alimentar, ficando muitas vezes apenas no âmbito dos movimentos sociais, instituições governamentais e ONGs.
\end{abstract}

Esta crise anunciada por Souza nos remete não só para crise de alimentos, mas uma crise no setor agrário, isto porque existem matrizes diferentes e divergentes, uma orientada para grandes projetos, aqui já tratada como agronegócio, e outra orientada para agricultura de subsistência, a agricultura familiar, que historicamente foi dependente de políticas públicas compensatórias, mas que ao longo do tempo vem resistindo ao avanço deste modelo de agricultura industrializada.

Percebe-se que a soberania alimentar é uma bandeira de luta dos movimentos sociais, que a abraçam como uma alternativa ao método neoliberal, de exploração e exclusão, que ao mesmo tempo é incapaz de solucionar o problema da comida do mundo. A soberania alimentar se sustenta na autonomia local, nos círculos locais de produção e consumo, na soberania energética e tecnológica e nos movimentos de agricultores familiares. Pautar a soberania alimentar é enfrentar as causas primordiais da fome, da pobreza e as tensas relações entre o desenvolvimento social equitativo e a conservação ecológica saudável, por isso os movimentos sociais compreendem que a restauração dos sistemas alimentares deve ser respaldada por alternativas de bases agroecológicas, só assim o enfrentamento será possível (ALTIERI, 2010).

\title{
Educação ambiental
}

A temática da educação ambiental no mundo é motivada a partir da crescente degradação ambiental a qual o planeta foi submetido, problemas como mudanças climáticas, aquecimento global, extinção de espécies vegetais e animais, vieram à tona. Neste cenário de destruição protagonizado principalmente pelas 
grandes empresas, o desmatamento para plantio das commodities foi posto pelos meios de comunicação como algo necessário para um projeto de desenvolvimento de país, reafirmando a máxima 'Vale tudo pelo lucro'. A vida urbana também tem suas responsabilidades frente a essa crise ambiental, o avanço das indústrias e a forte concentração populacional nas cidades acrescentam diversos problemas, entre eles está o acúmulo de lixo, esgotos sem o fim correto, emissão de gases do efeito estufa, poluição das águas e desmatamento.

Para Souza et al. (2012), a educação ambiental foi colocada neste cenário como uma ferramenta que poderia auxiliar na busca teórica e prática de soluções, surgindo como uma contribuição para o enfrentamento dos problemas ecológicos enfatizados mais fortemente a partir dos anos 1970. Uma espécie de consciência da crise ambiental vem movimentando todos os campos, de modos distintos e formas diferentes de tratar o tema vem tomando a cena. Desenhos animados, campanhas publicitárias, textos acadêmicos, matérias jornalísticas, documentários, obras de arte são alguns dos exemplos de abordagens da temática ambiental. Ocorre que, diante desta tematização proliferante, diferentes intencionalidades de discursos são apresentadas, alguns sem um compromisso ético e político com a real situação ambiental (RATTO et al., 2017).

São grandes as tentativas dos diversos meios de comunicação em conscientizar as pessoas sobre os comportamentos ambientais, mas pode-se suspeitar das intencionalidades de alguns destes meios. Para qual público eles estão falando? Qual discurso estão usando? Quais os meios utilizados? Como as pessoas são abordadas? Estas são algumas perguntas que precisam ser feitas para os meios de comunicação que abordam esta temática. A educação, por ser multidisciplinar, dialoga com diversas áreas, disciplinas e setores da sociedade civil, seja em campos públicos ou privados. Sobre a preocupação com as questões ambientais, Ratto et al. (2017), diz que

[...] parece que os medos e pavores da vida urbana vêm tomando força e se constituindo cada vez mais rápido. Um desses medos parece ser aquele que envolve as questões planetárias da continuidade da vida humana na Terra. Diante de tanta devastação ambiental, aquecimento global, toneladas de lixo produzidos por nós a cada dia, e tantos outros exemplos já referidos, percebemos que a preocupação com o meio ambiente se tornou questão central. Nesse sentido, não é à toa que vemos eclodir essa preocupação nas escolas, em Organizações Não-Governamentais, nas Redes de Supermercados, nos Bancos e, com toda potência, na mídia de forma geral.

Ainda alinhado às ideias de Ratto et al. (2017), em que os problemas socioambientais que se apresentam nesses contextos midiáticos não são exclusivos do Brasil, mas sim algo que vem tomando força e constituindo um sério problema mundial em suas esferas social, política, econômica e, evidentemente, ecológica, destaca-se que a potência dos enunciados que são colocados na mídia estão condicionados à veracidade dos mesmos e no discurso em que são colocados, que o resultado principal é a interferência em nosso comportamento, seja em formas de ações ou de posicionamentos.

De acordo com Cortes Junior et al. (2017), a educação ambiental se afirma como uma estratégia de intervenção, quando são divulgados em diversos canais os impactos das atividades humanas no meio ambiente, isso feito por diversos movimentos ambientalistas, institutos de pesquisas e órgão internacionais, mobilizando diversos atores da sociedade a desenvolver alternativas que buscam minimizar os impactos 
causados pelo avanço da degradação ambiental. A educação ambiental na educação (BRASIL, 2012) básica ou superior pode ser trabalhada de forma transversal, interagindo com os conteúdos das diferentes disciplinas, isto se formaliza também quando ela consta nos projetos pedagógicos das escolas.

Potencializar o tema educação ambiental nas escolas é promover o acesso dos estudantes, ao conhecimento ambiental numa perspectiva formativa de um sujeito com comportamentos ambientais desde sua infância, isso é possível com o trabalho a partir de uma perspectiva construtivista da realidade. Colocar os jovens diante de uma análise crítica da realidade ambiental é uma das tarefas da educação ambiental como disciplina. Assim, o presente trabalho parte do pressuposto que a educação ambiental não é patrimônio exclusivo das escolas, ou de uma disciplina, mas que a mesma deve ser tratada em diferentes espaços, de forma que toda a população de maneira intensiva tenha acesso a esta temática.

A proposta educacional que a educação ambiental busca, acontece na relação dialética com o outro, nos relacionamentos com próprios seres humanos e com as demais formas de vida de nosso planeta. Quando se escuta o que o outro fala, suas ideias, suas práticas, estas se projetam na organização das "minhas" ideias; permitindo posicionamentos ante às crises impostas ao nosso planeta. No diálogo, construímos saberes e nos reconhecemos como seres inacabados, conforme Luca et al. (2012), que diz que

Seres inacabados no sentido mais orgânico da palavra, estamos sempre em construção, em processo, em movimento. Nas interações, com e no mundo, encontrando significados e novos significantes. [...] Quando estamos conscientes de nosso inacabamento, percebemos com maior facilidade que há espaços para mudança e para aceitar o diferente. E a perspectiva do conviver com diferentes formas de ver o mundo, na diversidade das identidades, é também a perspectiva de trabalhar coletivamente. A educação ambiental nos oferece esse desafio: agir coletivamente, justamente o oposto do ser individual, tão arraigado nas práticas diárias de nossa sociedade.

Finalmente entendemos que a missão da educação ambiental é a mudança de comportamentos e atitudes das pessoas de todo o mundo, o movimento ambiental projeta-se para questões planetárias, uma questão de sobrevivência futura. Ancorado nesse diálogo, a educação ambiental se propõe a fazer e na perspectiva de promover reflexões nos modos de viver, pensar, sentir e agir, tanto individual quanto coletivamente, que situamos este trabalho nesta temática ambiental. Quando tocamos nos aspectos comportamentais, entendemos que os meios de comunicação têm papel fundamental nas atitudes das pessoas e por isso entendemos ser uma relação justa de se problematizar.

\section{Representações sociais postas em 'jogo': construções discursivas}

Como se procurou evidenciar até o presente momento, há projetos de sociedade diferentes para a composição/ocupação de territórios, especialmente o brasileiro. Tais têm sido construídos em bases antagônicas, conforme a perspectiva econômica que se quer ver implementada no país. De um lado, há uma produção com vistas ao agronegócio, e aos grandes investimentos, pautada muito mais pela quantidade e pela exportação, sem, necessariamente, evidenciar uma preocupação com o meio ambiente ou com uma produção saudável; por outro, as pequenas produções com vistas principalmente ao mercado interno, cujos discursos se fundam em um consumo mais racional, em que se procura demonstrar uma íntima relação entre saúde, meio ambiente e consumo. 
Artigos científicos, propagandas, entrevistas com pessoas e grupos sociais, incluindo ONGs, grupos empresariais ligados a essas diferentes perspectivas, reforçam posicionamentos diversos em relação aos produtos e tecnologias usadas para a produção de alimentos. Tais grupos buscam as mídias no sentido de não apenas de divulgar informações/produtos, mas também no sentido de que os meios de comunicação 'agendem ${ }^{3 \prime}$ os fatos/posicionamentos, 'impondo' à sociedade determinado assunto, ao mesmo tempo em que buscam produzir determinado comportamento sobre tal fato/fenômeno.

Como as mídias têm buscado alcançar maior difusão, agendam fatos, de modo a constituírem a realidade da forma que melhor lhes aprouver. Assim, determinados fenômenos, descobertas científicas ganham notoriedade das/nas mídias alcançando ampla penetração entre os diversos públicos, acirrando uma dicotomia que tem origem na ciência e na tecnologia de produção. Essa controvérsia, que pode ser denominada de acordo com a Psicologia Social como 'pressão à inferência', (MOSCOVICl, 2012) obriga a sociedade de amadores à tomada de posição.

Nesse sentido, as mídias constroem metáforas, afinam discursos, que permitem a construção de 'mitos' e de pensamentos científicos (logos) que se tornam objeto de conhecimento e passam a fazer parte de discussões nas "sociedades de amadores" (MOSCOVICI, 2012; MARKOVÁ, 2016). Divulgam-se, dessa forma, representações sobre os produtos e suas formas de produção, obrigando os sujeitos (comuns) a adotarem um posicionamento.

De acordo com Jodelet (2001) e Moscovici (2012), as representações sociais são formas de conhecimento do mundo, construídas a partir do agrupamento de conjuntos de significados que permitem dar sentido a fenômenos novos, constituindo um saber compartilhado, geral e funcional para os sujeitos, denominado de senso comum. Portanto, as RS constituem-se como um conjunto de conceitos relativos a formas de pensar, de agir e de sentir que se colocam no cotidiano de sujeitos individuais/coletivos, considerando as comunicações interindividuais ou públicas.

Nesse sentido, a imprensa tem um papel fundamental, visto que além de 'criar o fato' (Teoria do Agendamento), ela também o divulga e o faz propagar entre os sujeitos constituintes da 'sociedade de amadores', permitindo não só o acesso à informação, mas determinando quais informações e o 'tom' dessas informações, o que contribui para acirrar as dicotomias presentes nas diversas produções científicas. Cada uma dessas vertentes busca construir um conjunto de argumentos.

Moscovici (2012) afirma que as representações sociais se constituem como um fenômeno típico das sociedades modernas. A instauração do fenômeno de comunicação de massa permitiu o acesso maciço a contextos sociais específicos, bem como a emergência de diferentes grupos sociais de produção de conhecimento do senso comum e uma consequente diversificação das representações.

Outro ponto colocado por Moscovici (2012), em relação às RS, permite que seja pensado que essas se constroem em relação a objetos/fenômenos/fatos que apresentam uma possibilidade de 
posicionamentos diferentes. Tais fatos/fenômenos desestabilizam a ordem social, novamente obrigando à tomada de posições, porque se referem a um objeto complexo e "polimorfo" no dizer de Guimelli et al. (2015), colocando-o em um plano de incertezas, de desestabilização de conhecimentos, comportamentos e emoções anteriormente construídos.

As RS se constituem e são necessárias exatamente nesse plano de incertezas, porque são motivadas por 'novas' construções científicas, políticas e/ou econômicas, quer seja na produção de conhecimentos sobre determinado objeto, quer seja na adoção de outros olhares para esse fato/fenômeno. Um terceiro ponto a ser observado na construção de RS é que os fatos/fenômenos ou objetos (ou os olhares sobre) colocados mostram a necessidade de que esse seja inserido no cotidiano dos indivíduos ou grupos de modo a se tornar um conhecimento útil e partilhado no interior de um dado grupo.

Assim, o 'novo' se insere dentro de um contexto, ambiente político, ideológico, econômico, científico que lhe é preexistente, devendo se ancorar de modo a constituir 'novas' estabilidades e certezas, inserindose em um quadro conceitual, ideológico, político, científico já constituído. Desse modo e considerando a relação da mídia com o público, tanto consumidor, quanto produtor do conhecimento, as representações sociais também são construídas e difundidas por meio da interação pública entre atores sociais, em práticas de comunicação do cotidiano (MOSCOVICl, 2012).

Tais interações podem ocorrer, considerando-se três sistemas distintos de comunicação: Propaganda: sistema caracterizado por temas ordenados sistematicamente e bem definidos em antagonismos, cujo discurso se organiza com uma função primordialmente persuasiva, com o objetivo de alterar comportamentos; Propagação: estabelecido por membros de um grupo que possuem uma visão de mundo organizada em torno de uma crença a ser propagada; e Difusão: direcionado a um grupo social com identidade difusa, é moderada pela própria audiência tendo em vista que a informação aqui se constitui em produto, isto é, o objetivo é de simplesmente informar, o que contribui para a formação do saber comum.

Moscovici (2012) busca explicitar como os saberes, em nível social, permitem a coletividade processar um dado conhecimento veiculado pela mídia, transformando-o em uma propriedade impessoal, pública, que permite a cada indivíduo manuseá-lo e utilizá-lo de forma coerente com os valores e as motivações sociais da coletividade à qual pertence.

Para ele, a Psicologia Social deve se interessar pela cognição social, isto é, pela criação, entre os indivíduos, das representações consensuais do universo. Ainda para Moscovici (2012), a formação das representações sociais depende da qualidade e do tipo de informações sobre o objeto social de que o indivíduo dispõe, do seu interesse pessoal sobre aspectos específicos do objeto e da influência social no sentido de pressionar o indivíduo a utilizar informações dominantes no grupo.

Moscovici (2012) propõe uma relação particular entre sistemas de comunicação e as representações sociais, apoiado no caráter circulante e móvel de sua teoria. As representações sociais se modificam ou se atualizam dentro de relações de comunicação diferentes. Dessa forma, a mídia, integrada por um grupo de especialistas formadores e, sobretudo, difusores de representações sociais, é responsável pela estruturação de sistemas de comunicação que visam comunicar, difundir ou propagar determinadas representações. 
Nessa perspectiva, as imagens e as metáforas construídas pelas mídias na divulgação de um produto, de um conhecimento e/ou de um modo de vida são essenciais para a objetivação e ancoragem desses, pois além de divulgarem, podem contribuir para que a sociedade de amadores construa RS.

\section{Análise dos 'corpora' da pesquisa}

Observa-se, na figura 1, que, em primeiro plano, uma criança cuja aparência saudável e bonita, representa que carrega um tomate vermelho, cuja aparência é bastante saudável também, assim como a criança. Essa imagem repousa sobre um plano verde facilmente associado à natureza. A imagem da criança remete à inocência, pureza e necessidade de cuidados para um crescimento saudável e feliz. Em sociedades ocidentais contemporâneas a criança é vista como um sujeito que requer cuidados, dada a sua fragilidade e por estar em processo de formação.

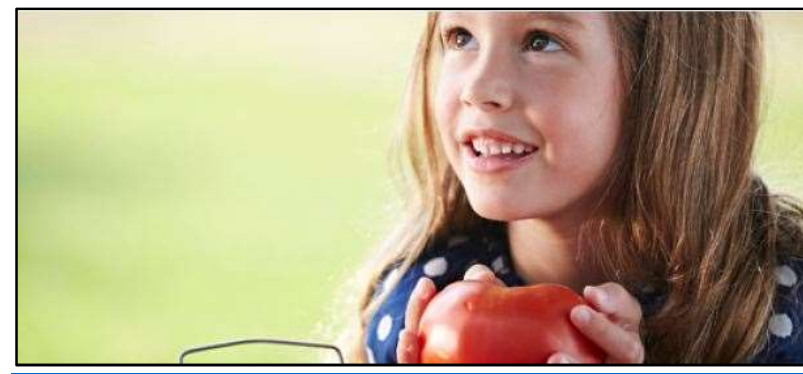

Figura 1: Publicação da Monsanto: Imagem de divulgação da produção da Monsanto.

Fonte: Monsanto (2016).

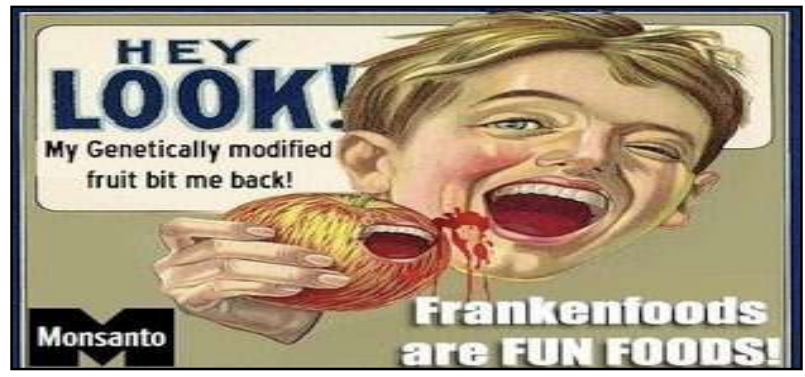

Figura 2: Imagem de reportagem mostrando a condenação da Monsanto denunciada por propaganda abusiva: Fonte: OngCea (2012).

A segurança é uma preocupação em relação a crianças, consideradas mais suscetíveis à contração de doenças. A exposição de crianças a ambientes que possam desconsiderar as normas de segurança pode incorrer em crime (abandono de incapaz) previsto não apenas no ECA, mas também Código Penal brasileiro: 'Art. 136 - Abandonar pessoa que está sob seu cuidado, guarda, vigilância ou autoridade, e, por qualquer motivo, incapaz de defender-se dos riscos resultantes do abandono'.

Como a imagem está localizada na página da Monsanto, a figura não poderia deixar de relacionar mesmo que de forma indireta a questões de segurança. Essa metáfora também se presentifica na figura 1, quando a menina esboça um sorriso e fixa o olhar em um plano mais alto, provavelmente direcionado à figura de um adulto (que não aparece no texto), mas que nos permite inferir sua presença.

Veja-se que a imagem da criança remete à ideia de segurança e boa alimentação, logo saúde. O ambiente tranquilo e a possível figura do adulto garantem a segurança necessária ao desenvolvimento da criança, e, por extensão a de quaisquer consumidores. As metáforas trabalham a perspectiva da dicotomia fragilidade $X$ segurança, a partir da associação entre saúde e proteção.

Por outro lado, a metonímia (presença do adulto), revelada no olhar ascendente da criança e do tomate colhido permitem pressupor a analogia 'fácil' o adulto presentificado no olhar da criança é a empresa que pode ser associada à figura que cuida. Logo, antecipa-se a legalidade da cena, à ilegalidade disseminada inclusive pela própria mídia que também acusa a empresa de uso 'indevido' de agrotóxicos que 
comprometem a qualidade e a soberania alimentar. A composição da cena enunciativa deixa entrever valores como: saúde, proteção, segurança ambiental, qualidade da produção que automaticamente associa todos esses elementos ao produto da Monsanto.

Quanto à figura 2, essa cena enunciativa apresenta uma composição verbal e não verbal; enfatize-se que nesse texto, existe uma gama de significações e representações anteriores ao próprio texto, mas que circulam nas sociedades. Retome-se inicialmente as metáforas presentes no alimento: a maçã. A maçã de cor vermelha (não tão vermelha quanto a imagem do tomate) compõe o primeiro plano da imagem. A mão que a carrega, embora muito próxima do real, é um "desenho", uma montagem e se encontra "descolada" do resto do corpo. Novamente uma criança a carrega, mas na figura se constitui como uma montagem, não uma fotografia.

A criança agora se encontra com a boca aberta, não se sabe se comendo ou se falando o texto que se encontra em segundo plano. A figura da criança adota uma postura feliz que coaduna com os dizeres colocados no cartaz: 'Frankenfoods are funfoods' que, em tradução livre, seria 'comidas Frankenstein são alimentos divertidos'. Evidenciam-se no texto algumas associações de caráter metafórico, tais como o personagem Frankenstein, criatura misto de humano e monstro, advinda de um 'criador' (médico/cientista) humano que busca construir outra criatura. A ciência se faz presente de forma sub-reptícia na figura da 'loucura' humana que busca transformar radicalmente o 'natural'.

Também o inusitado se faz presente quando se vê que a maçã também tem boca (aberta e cheia de dentes) o que realça o inusitado, mas ao mesmo tempo a associa ao 'Franken' (comidas de Frankenstein). Enfatize-se, ainda, o fato de se usar uma maçã, fruta cuja associação com a passagem bíblica é inevitável, pois foi a 'maçã que expulsou o homem do paraíso'. Daí a sua associação ao pecado, ao mal, metáforas subjacentes às 'falas' expressas no primeiro plano.

O texto: 'Hey, look! My genetically modifiedfruit bit me back ${ }^{4 \prime}$ realça dois aspectos: a modificação genética e o fato da fruta 'morder' assim como qualquer ser vivo, nesse caso, seres humanos. $\mathrm{O}$ sangue na figura empresta ao conjunto de enunciados verbais e não verbais um 'humor/terror', cujo objetivo maior não é fazer rir, mas intensificar a demonstração dos 'perigos' de modificações genéticas nos alimentos. Criam-se, pois, associações mentais com um conjunto de informações construídas socialmente e anteriormente ao texto em si, mas que são retomadas em ambos, que neste contexto, dialogam um com o outro.

Enquanto a figura 1 (produzida pela Monsanto) adota um 'tom' mais sério, e principalmente tenta passar uma imagem de proteção, a figura 2 (produzida por 'centro de estudos') ridiculariza de forma bemhumorada não somente aquele que produz, mas àquele que consome alimentos geneticamente modificados, atentando para os riscos à saúde. Finalmente, cumpre ressaltar a adoção de tons pastéis para o fundo da figura em oposição às cores quase pretas e brancas das letras ganham destaque na figura 2, de modo a provocar 'medo' nas pessoas. É um 'humor negro', em que os contrastes emprestam ao texto um

\footnotetext{
${ }^{4} \mathrm{Em}$ tradução livre: "Veja! Minha fruta geneticamente modificada me mordeu (de volta)". 
antagonismo a partir das metáforas existentes, mas que cumprem a função de criar a repulsa no consumidor/leitor.

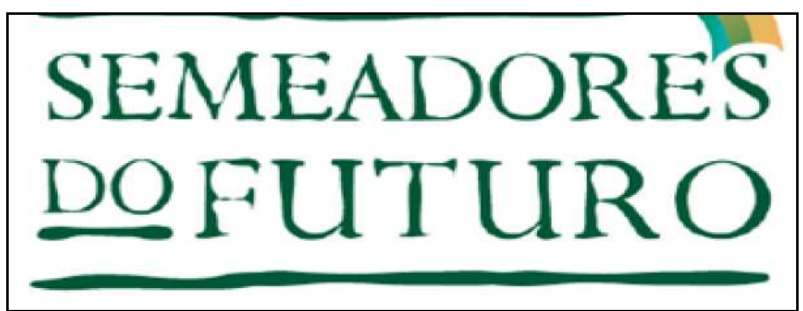

Figura 3: Projetos de ONGs brasileiras são reconhecidos e recebem US\$ 20 mil de apoio via Programa Semeadores do Futuro, da Monsanto Fundação. Fonte: Monsanto (2016).

Grandes empresas de capital nacional/internacional, geralmente mantêm uma fundação, como forma de construir uma imagem social de caráter mais assistencialista, com a finalidade de obter a adesão de consumidores em relação a seus produtos; é o que se denomina como 'responsabilidade social'. Normalmente, tais Fundações, por apresentarem esse caráter social, conseguem adeptos entre os consumidores, embora tais investimentos possam também alcançar dedução nos impostos a serem pagos. O Itaú, o Tixan/Ypê (empresa de produtos de limpeza) são algumas empresas que mantêm Fundações e/ou projetos com vistas ao social. A Monsanto, uma das maiores empresas produtoras de agrotóxicos, também tem uma Fundação com finalidade social, cujo teto de financiamento gira em torno de 20 mil reais.

Essas informações, contidas no sítio da Monsanto, servem como estratégias da empresa para a divulgação de um "nome social" mais preocupado com o caráter social da empresa, o que necessariamente ganha a adesão de consumidores, principalmente grupos de consumidores 'mais esclarecidos', logo mais exigentes em relação aos produtos que consomem. Nesse sentido, a página inicial da Monsanto apresenta informações sobre a 'Fundação Monsanto', tendo como slogan: 'Semeadores do futuro'.

A relação entre o nome 'semeadores' e as ações/produtos da Monsanto é bastante adequada, visto que a Monsanto não produz apenas agrotóxicos, também mantém um centro de pesquisas cujo objetivo é a produção de sementes geneticamente modificadas. O slogan é uma construção que, do ponto de vista linguístico, apresenta associações rápidas, curtas e fáceis de modo que o leitor/ouvinte o memorize rapidamente e construa uma adesão em maior grau ao produto/produtor.

As letras garrafais em tom verde permitem a associação à natureza de forma imediata e fácil. 0 consumidor não "tem" muito o que pensar ao ver o slogan, que é construído de forma a ganhar a sua adesão imediata, ancorando esse slogan a metáforas já constituídas e amplamente divulgadas, tais como verde/natureza; "Semeadores/plantar. O plantio exige tempo de espera e de produção de 'alimentos' para o futuro, suprimento de necessidades básicas e fundamentais na qualidade de vida dos seres humanos. 0 projeto 'Semeadores do Futuro' é seguido de fotografias de mulheres (negras e de baixa renda econômica) que produzem 'sacolas' a partir do material doado pela empresa Monsanto. Esse é um aspecto que busca produzir uma imagem positiva da empresa para consumidores que, dessa forma, não veem necessidade de constituírem oposição mais radical à essa. 
Sub-repticiamente, associa-se uma imagem de responsabilidade social à empresa, que busca subverter suas ações em relação ao meio ambiente e, por conseguinte, ao ser humano; e a questão da modificação genética torna-se 'esquecida'. O objetivo é realmente construir uma associação entre Monsanto/responsabilidade social e proteção do ser humano, assim como demonstrado na figura 1, já analisada. Há uma construção coerente no sítio da Monsanto que é demonstrado em sua página principal (home) em relação a uma empresa preocupada com pessoas e ambiente.

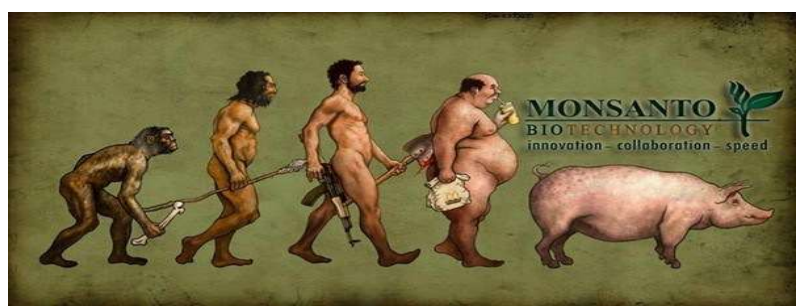

Figura 4: Indústria dos transgênicos: Nestlé, Cargil, Monsanto, Pepsico e Walmart.

Essa imagem faz parte de uma reportagem sobre a questão dos transgênicos, publicada em 2015, e, obviamente, a reportagem faz um conjunto de críticas a empresas que produzem modificações genéticas em alimentos (Nestlé, Cargil, Monsanto, dentre outras), atribuindo a tais modificações vários problemas de saúde verificados nas sociedades contemporâneas.

Assim, como a figura 2, já apresentada neste artigo, essa imagem busca produzir 'humor'. Esse viés humorístico ganha realce, pois, de imediato o leitor produz uma associação com uma figura bastante conhecida que trata da perspectiva (científica) de Darwin, relacionada à evolução humana. É a partir das ideias do evolucionismo darwiniano que se constroem as metáforas apresentadas ao leitor do texto da figura 4, e, que de certa forma, cria o 'humor' do texto. Detalham-se a seguir, os elementos textuais que ajudam o leitor a construir sentidos para o texto.

Em primeiro lugar retomem-se as imagens. A distribuição das imagens/figuras do texto propõe uma 'ordem' de leitura da esquerda para a direita. Enquanto na figura de Darwin o 'primeiro' primata não porta instrumento, na figura em tela, o 'primeiro' já segura um 'osso' à maneira de instrumento/armamento e apresenta uma posição que, embora de pé, ainda se aproxima do chão (como um quadrúpede).

A segunda figura da evolução, já se apresenta totalmente de pé, portando uma lança, o que pode induzir o leitor a associação com a caça, mas também a guerras que homens travam com outros homens por interesse em dominar o outro. A segunda imagem mantém traços primitivos em relação ao próprio corpo, representado pelo excesso de pelos, pela musculatura e, ainda pelo próprio instrumento que carrega.

O terceiro homem carrega em uma das mãos uma pá, que parece suja de algo vermelho - associação com sangue/terra, e, na outra, uma arma já da 'era moderna'. Essa imagem remete necessariamente a ações bélicas em que povos, grupos, pessoas impõem dominações sobre outros(as), estabelecendo uma clara alusão à força, à violência, à morte.

Finalmente, a última figura humana, aparece para 'quebrar' a lógica de construção textual: gordo, portando objetos de plástico na mão (copo e canudo), um 'saco' de alimentos na outra constroem uma clara alusão a alimentos industrializados, comuns nas sociedades modernas. O homem apresentado apresenta 
sérios problemas de obesidade, com um corpo nu, que ao contrário de exaltar a sensualidade da nudez, provoca certa repulsa aos olhos. Tal repulsa alcança o ápice ao se colocar em seguida a imagem de um "porco" suficientemente gordo e grande, 'pronto' para o consumo em larga escala.

Essa 'quebra' da lógica de construção textual surpreende o leitor de modo que ao provocar o 'humor' oportuniza a reflexão no sentido de se pensar o que se come e como o homem moderno passa a lidar com a própria alimentação. Estabelece-se uma cadeia sequencial de transformações, mas ao contrário do 'textualmente' esperado, apresenta-se uma 'involução' que a partir das transformações 'genéticas' produz um homem obeso, que de fato, não evolui, mas retorna a formas não humanas em seu processo de dominação do ambiente, incluindo aí outros homens.

Além disso, deve-se lembrar que o termo 'porco', em várias culturas ocidentais, quando usado como adjetivo torna-se uma característica pouco positiva, nada apreciável, pois remete a ideias como sujeira, gordura, comportamentos impróprios de seres humanos, quer em relação ao caráter, quer em relação aos aspectos físico/comportamentais.

Em relação, ainda, ao terceiro homem comparando-o aos demais, esse se mostra completamente ereto, passos firmes, musculatura perfeita; uma associação talvez com uma 'frase' (obra) 'assim caminha a humanidade' que foi evoluindo e cuja evolução o leva à destruição de si, do ambiente e da humanidade, retornando ao estágio 'desumano' inicial.

Finalmente, os enunciados verbais: compostos pela 'Monsanto' e sua logomarca seguida de termos como 'biotecnologia' - cuja associação com o progresso é evidente, mas também remete a modificações genéticas; em seguida as expressões: 'inovação, colaboração, rapidez' que podem tranquilamente serem associadas às propostas das empresas representadas nesse caso, pela Monsanto, em oposição ao próprio conteúdo das imagens do texto em tela. Se essas últimas expressões/enunciados se ligam à modernidade, tecnologia, progresso, qual seria a significação que tomam no contexto do texto?.

De fato, tais enunciados no contexto ${ }^{5}$ querem sugerir uma ironia em relação às empresas que fazem uso da biotecnologia no sentido que é construído na interrelação entre autor/leitor mediada pelo texto. Interessante que esses termos remetem ainda a figura do 'porco' apresentado, o que enfatiza o humor 'negro' do texto, dado que não é engraçado o fato de as pessoas adoecerem devido ao consumo de determinados alimentos.

Finalmente, chama-se a atenção para a palavra speed; a tradução mais literal desse termo seria 'rapidez, aceleração'. Porém, o dicionário 'Lingue' (online) também apresenta uma tradução para o termo relacionando-o a 'drogas' (anfetaminas) que, como é do conhecimento geral, são drogas usadas para o 'crescimento' da musculatura, o que torna as pessoas que as ingerem (sem prescrição médica) mais musculosa, porém provoca danos à saúde dos indivíduos, as quais com o tempo, apresentam uma flacidez muscular que pode deformar a aparência de seus consumidores. Essa ideia acentua a ironia contextual, visto que se associa à figura do porco também apresentada no texto.

${ }^{5}$ Contexto: são as relações internas - semânticas, sintáticas, morfológicas - a um determinado texto, isto é, são as relações constituídas pelos autores/leitores do texto em seus aspectos linguísticos de cada uma das partes do texto. 


\section{CONSIDERAÇÕES FINAIS}

Buscou-se, neste trabalho, apresentar algumas possibilidades permitidas pela Teoria das Representações Sociais, em aspectos que se relacionam a leituras de textos e as construções de sentido (s) para eles. Observa-se que o agendamento de fatos, produzidos pelas mídias (científicas ou não) podem construir antagonismos que podem acirrar no leitor as pressões à inferência que, por sua vez, reafirmam a necessidade de tomada de posição.

As primeiras conclusões relacionam-se à percepção da mídia como produtora de um tratamento da informação refratando informações que contribuem para a construção/consolidação de representações sociais e a existência de uma polarização dicotômica, propagada pela mídia. A observação de imagens veiculadas na mídia mostram os efeitos de sentido produzidos, com foco na análise do discurso e no caráter dialógico dos discursos, bem como a intencionalidade de imagens a partir de quem as publica. Foi possível perceber uma postura defensiva por parte da Monsanto e uma postura com vistas à produção de denúncias, por parte das ONGs. Essas diferentes posições enunciativas representam as intencionalidades dos enunciadores com vistas à formação das representações sociais dos sujeitos, uma vez que esta representação é formada pela qualidade e pelo tipo de informações disponíveis/construídas sobre o objeto.

Os discursos publicitários objetivam o acirramento de oposições, de caráter dicotômico, e, quer pela ironia, quer pelas metáforas produzem discursos antagônicos, pressionando os interlocutores no sentido de uma 'tomada de decisão'. Pode-se dizer, que a partir de tal confronto, os discursos publicitários contribuem para a formação de representações sociais, deixando entrever uma 'disputa' de poder pelos sujeitos leitores dessas mensagens, revelado ora pela aceitação ora pela negação das mensagens veiculadas.

É possível notar uma atitude dramatizada nas mensagens, ou seja, em diversos momentos os interlocutores, produtores de mensagens, colocam-se em uma função defensiva/acusativa, que, a partir de processos metafóricos construídos para a defesa de posicionamentos antagônicos, argumentam em função de determinada postura.

Os processos de difusão de informações e de propagação de ideias se evidenciam, provocando pressão à inferência nos interlocutores que dialogam e buscam construir sentidos para as mensagens veiculadas, ancorando-as em conhecimentos/representações anteriores. Nessas condições, é possível pensar o discurso como uma prática social, por considerar que eles são capazes de revelar os limites sociais construindo as relações antagônicas, sobre determinado fato agendado pelas mídias.

Dados os limites deste trabalho, os textos foram discutidos de forma breve, além de não se aprofundarem mais claramente nas possibilidades de reinterpretação que a TRS nos permite. Entretanto, espera-se ter demonstrado, mesmo que brevemente, as possibilidades colocadas pela teoria, que em uma perspectiva multi e transdisciplinar, aponta subsídios interessantes, inclusive para a análise e compreensão de metáforas contidas em textos midiáticos, as quais constituem um rico campo de exploração e estudos a serem realizados. 


\section{REFERÊNCIAS}

ALTIERI, M.. Agroecologia, agricultura camponesa e soberania alimentar. Nera, Presidente Prudente, n.16, p.2232, 2010.

ALTIERI, M.. Agroecologia: a dinâmica produtiva da Agricultura Sustentável. 4 ed. Porto Alegre: EDUFRGS, 2004.

AYUKAWA, M. L.. Limites e Possibilidades do Ensino de Agroecologia: um estudo de caso sobre o currículo do curso técnico agrícola da Escola Agrotécnica Federal de Rio do Sul/SC. Dissertação (Mestrado em Desenvolvimento Rural) Universidade Federal do Rio Grande do Sul, Porto Alegre, 2005.

BERNSTEIN, H.. Soberania alimentar: uma perspectiva cética. Sociologias, Porto Alegre, v.17, n.39, p.276-336, 2015. DOI: http://doi.org/10.1590/15174522-017003912

BRASIL. Ministério da Educação. Diretrizes Curriculares Nacionais para Educação Ambiental: CNE/CP. Brasília: ME, 2012.

CAPORAL, F. R.. Extensão Rural e Agroecologia. Recife: Bagaço, 2015.

CHONCHOL, J.. A Soberania Alimentar. Estudos Avançados, v.19, n.55, p.33-48, 2005. DOI: http://doi.org/10.1590/S0103-40142005000300003

CORTES JUNIOR, L. P.; SÁ, L. P.. Conhecimento pedagógico do conteúdo no contexto da educação Ambiental: uma experiência com mestrandos em ensino de ciências. Revista Brasileira de Ensino e Pesquisa em Educação em Ciências, Belo Horizonte, v.19, p.1-22, 2017. DOI: http://doi.org/10.1590/1983-21172017190105

FERNANDES, B, M.. Os campos de pesquisa em Educação do Campo: espaço e território como categorias essenciais. In: MOLINA, M. C.. Educação do Campo e Pesquisas: Questões para reflexão. Brasília: MDA, 2006.

GUTERRES, I.. Agroecologia militante: contribuições de Ênio Guterres. São Paulo: Expressão Popular, 2006.

HESPANHOL, R. A. M.. Agroecologia: Limites e Perspectivas. In: ALVES, A. F.; CARRIJO, B. R.; CANDIOTTO, L. Z..

Desenvolvimento Territorial e Agroecologia. São Paulo: Expressão Popular, 2008. p.117-136.

JODELET, D.. Representações sociais: Um domínio em expansão. In: JODELET, D.. As representações sociais. Rio de Janeiro: EDUERJ, 2001.

LEÃO, G.; ANTUNES-ROCHA, M. I.. Juventudes no/do campo: questões para um debate. In: LEÃO, G.; ANTUNES-ROCHA,
M. I.. Juventudes do Campo. Belo Horizonte: Autêntica, 2015.

LUCA, A. Q.; ANDRADE, D. F.; SORRENTINO, M.. O Diálogo como Objeto de Pesquisa na Educação Ambiental. Educação e Realidade, Porto Alegre, v.37, n.2, p.589-606, 2012. DOI: http://doi.org/10.1590/S2175-62362012000200014

MARKOVÁ, I.. Mente dialógica: Senso comum e ética. São Paulo: 2017

MOLINER, P.; GUIMELLI, C.. Les représentations sociales: Fondements théoriques e développement recents. Grenoble: Presses universitaires de Grenoble, 2015.

MONSANTO. Companhia Monsanto. Alimentação Infantil: Criança inteligente come bem. São Paulo: MONSANTO, 2016.

MONSANTO. Companhia Monsanto. Projetos de ONGs brasileiras são reconhecidos e recebem US\$ $\mathbf{2 0}$ mil de apoio via Programa Semeadores do Futuro. São Paulo: MONSANTO, 2016.

MOSCOVICl, S.. A Psicanálise, sua imagem e seu Público. Petrópolis: Vozes, 2012.

MOSCOVICI, S.. Representação Social: Investigação em Psicologia Social. Petrópolis: Vozes, 2003.

OngCea. Centro de Estudos Ambientais. Justiça Federal condena Monsanto por propaganda enganosa e abusiva. Rio Grande: OngCea, 2012.

RATTO, C. G.; HENNING, P. C.; ANDREOLA, B. A.. Educação Ambiental e suas Urgências: a constituição de uma ética planetária. Educação e Realidade, Porto Alegre, v.42, n.3, p.1019-1034, 2017. DOI: http://doi.org/10.1590/2175623659438

ROSSET, P.. Soberania Alimentar: manifesto global dos movimentos campesinos. Oakland: Institute for Food and Development Policy, 2003.

SOUZA, A. S.. Um debate acerca da soberania alimentar e da agroecologia: um desafio de percepção e de prática. Ou, de que lado é o meu quintal?. Pegada, v.10, n.1, p.113-133, 2009. DOI: https://doi.org/10.33026/peg.v10i1.1682

SOUZA, D. C.; SALVI, R. F.. A pesquisa em educação ambiental: um panorama sobre sua construção. Revista Brasileira de Ensino e Pesquisa em Educação em Ciências, Belo Horizonte, v.14, n.3, p.111-129, 2012. DOI: http://doi.org/10.1590/1983-21172012140308

A CBPC - Companhia Brasileira de Produção Científica (CNPJ: 11.221.422/0001-03) detém os direitos materiais desta publicação. Os direitos referem-se à publicação do trabalho em qualquer parte do mundo, incluindo os direitos às renovações, expansões e disseminações da contribuição, bem como outros direitos subsidiários. Todos os trabalhos publicados eletronicamente poderão posteriormente ser publicados em coletâneas impressas sob coordenação da Cognitionis Publishing, da Companhia Brasileira de Produção Científica e seus parceiros autorizados. Os (as) autores (as) preservam os direitos autorais, mas não têm permissão para a publicação da contribuição em outro meio, impresso ou digital, em português ou em tradução. 